\title{
Do we Achieve the Targets for Diabetic Patients; Deep Looks to Primary Care Practice
}

Almoutaz Alkhier Ahmed ${ }^{1 *}$ and Abdulellah Qurashi ${ }^{2}$

${ }^{1}$ ESH clinical Hypertension specialist, Saudi Arabia

2Primary Care Department, National Guard health affairs/WR, Saudi Arabia

"Corresponding author: Almoutaz Alkhier Ahmed, Primary Care Department, Waha Medical Specialist Center / NGHA-Jeddah-KSA, Tel: 00966508907285; E-mail: khier2@yahoo.com

Received date: Feb 06, 2014, Accepted date: Mar 20, 2014, Published date: Mar 25, 2014

Copyright: (c) 2014 Ahmed, et al. This is an open-access article distributed under the terms of the Creative Commons Attribution License, which permits unrestricted use, distribution, and reproduction in any medium, provided the original author and source are credited.

\begin{abstract}
Introduction: Diabetes care to the standard targets is an art need trained health care provider's work in harmony. It is not an easy job; it is a continuous process of hard team works. Primary care practice is a busy practice where diabetes care is part of a complex daily care covering other health problems. In spite of this multiple daily care services, we raised the question if our care took our patients to meet target goals settled by the American diabetes association or not?. Assessing the current situation is the first step to catch the standards.
\end{abstract}

Objectives: To determine the degree of glycemic control by using $\mathrm{HbA} 1 \mathrm{c}$ and lipid profile control by measuring total cholesterol, low density lipo-protein, high density lipo-protein and triglycerides.

To detect variations in $\mathrm{HbA1c}$, lipid or Vit D control during the year 2013

Methodology: Cross sectional study was designed and conducted at Alwaha medical specialist center; one of the National Guard health affairs / WR primary care centers. Chronic disease registry was designed. A list of 1224 diabetic patients' records were reviewed and 302 patients' records were randomly selected. HbA1c values were detected with total cholesterol (T-Chol), low density lipoprotein (LDL) and vitamin D. HbA1c and lipid profiles were clustered into three groups; group A (1st Jan - 30st April 2013), group B (1st May - 31st August 2013). Group C (1st Sep - 31st Dec 2013). The American Diabetes Association 2014 target goals for diabetic patients were adopted. Data was collected and analyzed using SPSS software.

Results: Three hundred and two, medical records were reviewed (110 males, 192 females) with mean age 57.31 \pm 11.47. The overall means of HbA1c $8.73 \pm 2.04$, total cholesterol (T-Chol) $4.6 \pm 1.17 \mathrm{mmol} / \mathrm{L}$, low density lipoprotein (LDL) $2.7 \pm 0.85 \mathrm{mmol} / \mathrm{L}$, high density lipoprotein (HDL) $1.02 \pm 0.23 \mathrm{mmol} / \mathrm{L}$, Triglyceride (TG) $1.68 \pm$ $1.08 \mathrm{mmol} / \mathrm{L}$ and vitamin $\mathrm{D} 42.32 \pm 22.56 \mathrm{nmol} / \mathrm{l}$ were calculated as shown. There were no statistical differences in $\mathrm{HbA} 1 \mathrm{c}$ between groups $\mathrm{A}$ vs $\mathrm{B}$ or $\mathrm{C}(7.65 \pm 3.49$ vs $8.03 \pm 2.85$ and $7.69 \pm 3.28)$, P values were 0.3 and 0.9 . For Vit $\mathrm{D}$ means there were no statistical differences between groups $(32.46 \pm 26.12 \mathrm{nmol} / \mathrm{l} \mathrm{vs} 31.83 \pm \mathrm{nmol} / \mathrm{l}$ and $29.54 \pm$ $29.68 \mathrm{nmol} / / ; \mathrm{P}$ values were 0.8 and 0.36

There was no statistically difference between male and female in their overall mean $\mathrm{HbA} 1 \mathrm{c}$ values (HbA1c $8.49 \pm$ 1.86 vs $8.86 \pm 2.14$ ); $\mathrm{P}$ value was 0.13 .

Males showed better LDL means than females; $2.54 \pm 0.88$ vs $2.81 \pm 0.83$ ( $P$ value 0.0082 ).

Interestedly, those who did there $\mathrm{HbA} 1 \mathrm{c}$ once, twice and thrice were $42.4 \%, 31.8 \%$ and $25.8 \%$ respectively while $61.2 \%$ meet ADA HbA1c target goal.

Conclusion: Targeted glycemic and lipid control was difficult to achieve in primary care setting. More studies were recommended to analyzed barriers to achieve control and how to overcome them.

Keywords: Diabetes; Glycemic control; Lipid control; VitD, Primary care

\section{Abbreviations}

HbAlc: Glycated Haemoglobin; T-Chol: Total Cholesterol; LDL: Low Density Lipoprotein; HDL: High Density Lipoprotein; TG:
Triglyceride; GP(s): General Practitioner(s); CVDs: Cardiovascular Diseases

\section{Introduction}

Diabetes mellitus is one of the most common chronic disorders worldwide, affecting people of all age groups. The prevalence of 
diabetes increases with age-at least one in ten older people resident within the UK have diabetes. Diabetes is also more common in people of South Asian, African and African Caribbean origin. The World Health Organization predicts a doubling of the number of people with diabetes worldwide between 1995 and 2010 [1]. Diabetes is a leading cause of blindness, kidney failure and limb amputation and greatly increases the risk of coronary heart disease and stroke. It can also threaten the successful outcome of pregnancy. Diabetes accounts for at least 5 per cent of healthcare costs. Up to 10 per cent of hospital inpatient resources are used to care for people with diabetes [2].

Meticulous metabolic control can prevent or delay the onset of the complications of diabetes. The impact of these complications can also be greatly reduced if they are detected early and appropriately managed. Thus, regular surveillance for and early diagnosis of the complications of diabetes are also important.

In view of the high risk of cardiovascular disease in people with diabetes, particularly those with Type 2 diabetes, the careful management of other cardiovascular risk factors, including smoking, physical inactivity and especially hypertension and dyslipidaemia, is essential.

The overall aim of diabetes care is to enable people with diabetes to achieve a quality of life and life expectancy similar to that of the general population.

Assessing the current situation is the first step in any improvement process. Analysis of the current situation usually raise the perception of working teams on the necessity of catching international standards as long as they did not meet them.

The maintenance of near normal blood glucose levels is crucial to the prevention of the microvascular complications of diabetes [3,4]diabetic retinopathy, diabetic renal disease and diabetic neuropathy-as well as to the alleviation of the symptoms of diabetes and the avoidance of the acute metabolic crises (hypoglycaemia and ketoacidosis).

The provision of diabetes services is complex-care is provided by a wide range of professionals, including general practitioners (GPs) and other primary healthcare professionals and specialist diabetes teams, as well as people with diabetes and their careers. The achievement of good outcomes for people with diabetes is dependent on the provision of well-organized and coordinated diabetes services that draw on the knowledge and skills of health and social care professionals working across primary and secondary care.

It is usually the GP who makes the initial diagnosis of diabetes and it is usually the GP who is responsible for agreeing with the person with diabetes where they will receive each element of their diabetes care and who will provide this. Increasingly, the routine follow up of people with diabetes is also undertaken within primary care.

Maintaining optimal glycemic control is an important goal of therapy in patients with diabetes mellitus.

\section{Methodology}

Alwaha Medical specialist center is one of the National Guard health affairs-west region primary care centers. The services were presented to National Guard employees and their families exclusively and to those who have permissions. The majority of our patients were Saudi. All diabetic patients were usually reviewed every 4 months unless there is need for nearest appointment. Cross sectional study was designed and conducted at Alwaha medical specialist center. Chronic disease registry was designed. A list of 1224 diabetic patients 'records were reviewed and 302 patients' records were randomly selected. HbAlc values were detected with total cholesterol (T-Chol), low density lipoprotein (LDL) and vitamin D. HbAlc and lipid profiles were clustered into three groups; group A (1st Jan - 30st April 2013), group B (1st May - 31st August 2013). Group C (1st Sep - 31st Dec 2013). The American Diabetes Association 2014 target goals for diabetic patients were adopted.

Criteria for selection were settled:

i) Subjects should be Saudi

ii) Subjects should have diabetes type 2

iii) Subjects should not have overt cardiovascular diseases

iv) Subjects should have active medical record during the year 2013

All selected medical records lab results were reviewed from the period of 1st Jan-31 Dec 2013. HbA1c, T. Chol, LDL, HDL, Vit D results were collected. Subject medical record was reviewed once.

American Diabetes Association 2014 target goals were adopted [5] (Table 1).

\begin{tabular}{|l|l|l|l|l|l|}
\hline HbA1c & T.Chol & LDL* $^{*}$ & HDL & TG & Vit D \\
\hline$<7 \%$ & $<4 \mathrm{mmol} / \mathrm{L}$ & $\begin{array}{l}<2.6 \\
\mathrm{mmol} / \mathrm{L}\end{array}$ & $\begin{array}{l}1 \mathrm{mmol} / \mathrm{L} \text { in male } \\
>1.3 \mathrm{mmol} / \mathrm{L} \text { in } \\
\text { female }\end{array}$ & $\begin{array}{l}<1.7 \\
\mathrm{mmol} / \mathrm{L}\end{array}$ & $\begin{array}{l}>50 \\
\mathrm{nmol} / \mathrm{l}\end{array}$ \\
\hline
\end{tabular}

Table 1: American Diabetes Association target goals, ${ }^{*}$ Patients without overt cardiovascular diseases.

Data analysis was done using SPSS software. Means and standard deviations were calculated. Chi-square test was used to determine statistical significant differences between variables, defined as significant for a $\mathrm{p}$-value $<0.05$.

\section{Results}

Three hundred and two (302) subjects were included in this study (110 males and 192 females). The mean age was $57.31 \pm 11.47$ (Table 2).

\begin{tabular}{|l|l|l|}
\hline & Male & Female \\
\hline Total & 110 subjects (36.5\%) & 192 subjects (63.5\%) \\
\hline Age & $57.71 \pm 12.59$ & $57.07 \pm 10.84$ \\
\hline DM duration & $17.56 \pm 10.56$ & $19.47 \pm 8.5$ \\
\hline Number of participants & 110 & 192 \\
\hline Nationality & Saudi & Saudi \\
\hline Recorded CVDs & 0 & 0 \\
\hline
\end{tabular}

Table 2: Participants characters.

The over-all HbAlc mean was $8.73 \pm 2.04(95 \% \mathrm{CI} \pm 0.23)$. The over-all T. Chol, LDL, HDL and TG means were $4.6 \pm 1.17(95 \% \mathrm{CI} \pm$ $0.13), 2.7 \pm 0.85(95 \% \mathrm{CI} \pm 0.1), 1.02 \pm 0.23(95 \% \mathrm{CI} \pm 0.03), 1.68 \pm 1.08$ 
Citation: Ahmed AA, Qurashi A (2014) Do we Achieve the Targets for Diabetic Patients; Deep Looks to Primary Care Practice. J Gen Pract 2:

Page 3 of 7

$(95 \% \mathrm{CI} \pm 0.12)$ respectively. For Vit $\mathrm{D}$, the over-all mean was $42.32 \pm$ $22.56(95 \% \mathrm{CI} \pm 2.54)$ (Table 3) (Figures 1A-F).

HbA1c means were cluster into three group based on time interval; Group A (1 Jan-30 April 2013), group B (1 May-31 Aug 2013) and group C (1 Sep-31 Dec 2013). The means for group A, B and C were $8.03 \pm 2.85,7.69 \pm 3.28$ and $7.65 \pm 3.49$ respectively. There was no statistical difference between groups (Table 4).

In subanalysis for differences between males and females subjects, we noticed statistical differences between LDL means; $2.54 \pm 0.88$ vs

\begin{tabular}{|l|l|l|l|l|l|}
\hline HbA1c & T.Chol mmol/L & LDL mmol/L & HDL $\mathbf{~ m m o l} / \mathbf{L}$ & TG $\mathbf{~ m m o l} / \mathbf{L}$ & Vit $\mathbf{D}$ nmol/L \\
\hline $8.73 \pm 2.04$ & $4.6 \pm 1.17$ & $2.7 \pm 0.85$ & $1.02 \pm 0.23$ & $1.68 \pm 1.08$ & $42.32 \pm 22.56$ \\
$(95 \% \mathrm{Cl} \pm 0.23)$ & $(95 \% \mathrm{Cl} \pm 0.13)$ & $(95 \% \mathrm{Cl} \pm 0.1)$ & $(95 \% \mathrm{Cl} \pm 0.03)$ & $(95 \% \mathrm{Cl} \pm 0.12)$ & $(95 \% \mathrm{Cl} \pm 2.54)$ \\
\hline
\end{tabular}

Table 3: American Diabetes Association target goals.

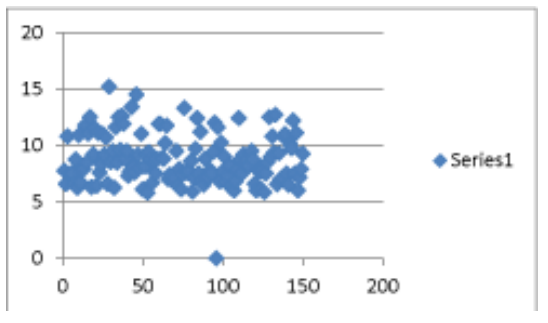

Figure 1A: Scatter of HbA1c\% participants means of 2013.

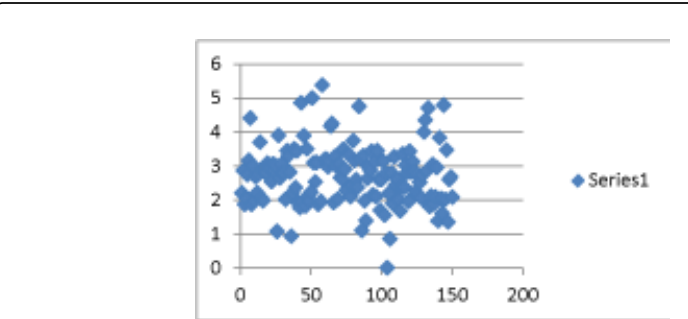

Figure 1C: Scater of LDL mmol/L participants means of 2013.
$2.81 \pm 0.83(\mathrm{P}$ value 0.0082$)$ and for HDL means; $0.9 \pm 0.22$ vs $1.09 \pm$ 0.22 (P value 0.0001) (Table 5 and Figure 2).

There was statistical difference in HbAlc male and female cluster groups between group $\mathrm{B}$ and $\mathrm{C} ; 8.28 \pm 2.98$ vs $6.69 \pm 3.46$ (P value 0.0001 ) and $8.16 \pm 3.39$ vs $6.64 \pm 3.51$ ( $\mathrm{P}$ value 0.0003 ) respectively. For Vit $\mathrm{D}$, it was statistically different through all groups ( $\mathrm{P}$ value 0.0001 ) (Table 6, Figures 3 and 4).

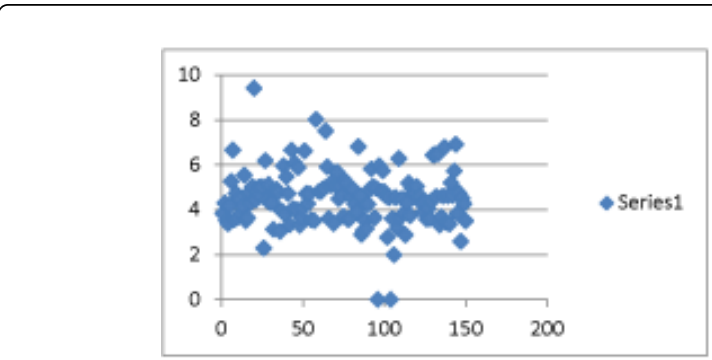

Figure 1B: Scater of T.Chol mmol/L participants means of 2013.

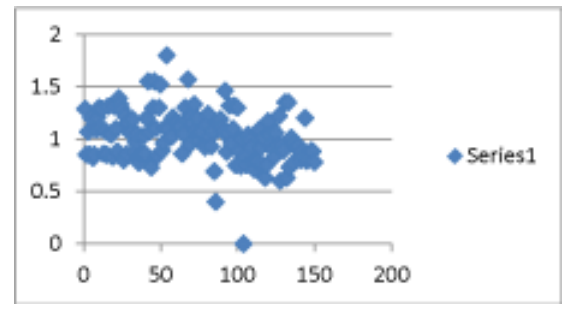

Figure 1D: Scater of HDL mmol/L participants means of 2013.

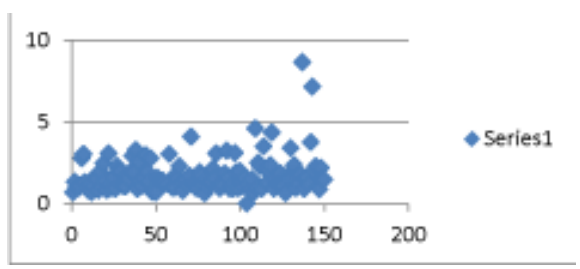

Figure 1E: Scater of TG mmol/L participants means of 2013.

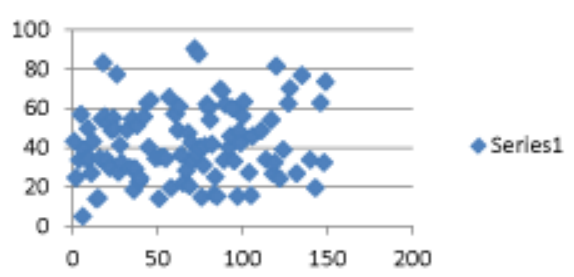

Figure 1F: Scater of Vit D nmol/L participants means of 2013. 
Citation: Ahmed AA, Qurashi A (2014) Do we Achieve the Targets for Diabetic Patients; Deep Looks to Primary Care Practice. J Gen Pract 2:

Page 4 of 7

\begin{tabular}{|l|l|l|l|l|l|}
\hline HbA1c & T.Chol $\mathbf{~ m m o l} / \mathbf{L}$ & LDL $\mathbf{~ m m o l} / \mathbf{L}$ & HDL $\mathbf{~ m m o l} / \mathbf{L}$ & TG $\mathbf{~ m m o l} / \mathbf{L}$ & Vit D $\mathbf{~ n m o l} / \mathbf{L}$ \\
\hline $8.73 \pm 2.04$ & $4.6 \pm 1.17$ & $2.7 \pm 0.85$ & $1.02 \pm 0.23$ & $1.68 \pm 1.08$ & $42.32 \pm 22.56$ \\
$(95 \% \mathrm{Cl} \pm 0.23)$ & $(95 \% \mathrm{Cl} \pm 0.13)$ & $(95 \% \mathrm{Cl} \pm 0.1)$ & $(95 \% \mathrm{Cl} \pm 0.03)$ & $(95 \% \mathrm{Cl} \pm 0.12)$ & $(95 \% \mathrm{Cl} \pm 2.54)$ \\
\hline
\end{tabular}

Table 4: Over all glycemic control and vit D means through 2013 (4 months interval cluster).

\begin{tabular}{|l|l|l|l|}
\hline & Male & Female & P value \\
\hline HbA1c $\%$ & $8.49 \pm 1.86$ & $8.86 \pm 2.14$ & 0.13 \\
\hline T.chol mmol/L & $4.37 \pm 1.35$ & $4.61 \pm 1.14$ & 0.10 \\
\hline LDL mmol/L & $2.54 \pm 0.88$ & $2.81 \pm 0.83$ & 0.0082 \\
\hline HDL mmol/L & $0.90 \pm 0.22$ & $1.09 \pm 0.22$ & 0.0001 \\
\hline TG mmol/L & $1.92 \pm 1.49$ & $1.54 \pm 0.72$ & 0.63 \\
\hline Vit D nmol/L & $46.41 \pm 31.02$ & $40.96 \pm 18.98$ & 0.059 \\
\hline
\end{tabular}

Table 5: Male vs Female glycemic and lipid control.

\begin{tabular}{|c|c|c|c|c|c|c|}
\hline & $\begin{array}{l}\text { HbA1c\% } \\
\text { Group A } \\
\text { 1st Jan-31st April } \\
2013\end{array}$ & $\begin{array}{l}\text { HbA1c\% } \\
\text { Group B } \\
31 \text { st May- 31st Aug } \\
2013\end{array}$ & $\begin{array}{l}\text { HbA1c\% } \\
\text { Group C } \\
\text { 1st Sep- 31st Dec } \\
2013\end{array}$ & $\begin{array}{l}\text { Vit D nmol/L } \\
\text { Group A } \\
\text { 1st Jan- 31st April } \\
2013\end{array}$ & $\begin{array}{l}\text { Vit D nmol/L } \\
\text { Group B } \\
\text { 1st May- 31st Aug } \\
2013\end{array}$ & $\begin{array}{l}\text { Vit D nmol/L } \\
\text { Group C } \\
\text { 1st Sep- 31st Dec } \\
\text { April 2013 }\end{array}$ \\
\hline Female & $8.02 \pm 2.85$ & $8.28 \pm 2.98$ & $8.16 \pm 3.39$ & $28.54 \pm 31.28$ & $24.99 \pm 30.95$ & $28.32 \pm 25.71$ \\
\hline Male & $8.03 \pm 2.88$ & $6.69 \pm 3.46$ & $6.64 \pm 3.51$ & $39.1 \pm 25.63$ & $38.16 \pm 25.76$ & $44.41 \pm 24.95$ \\
\hline$P$ value & 0.97 & 0.0001 & 0.0003 & 0.003 & 0.0001 & 0.0001 \\
\hline
\end{tabular}

Table 6: Male vs female glycemic control and vit D means through 2013 (4 months interval cluster).
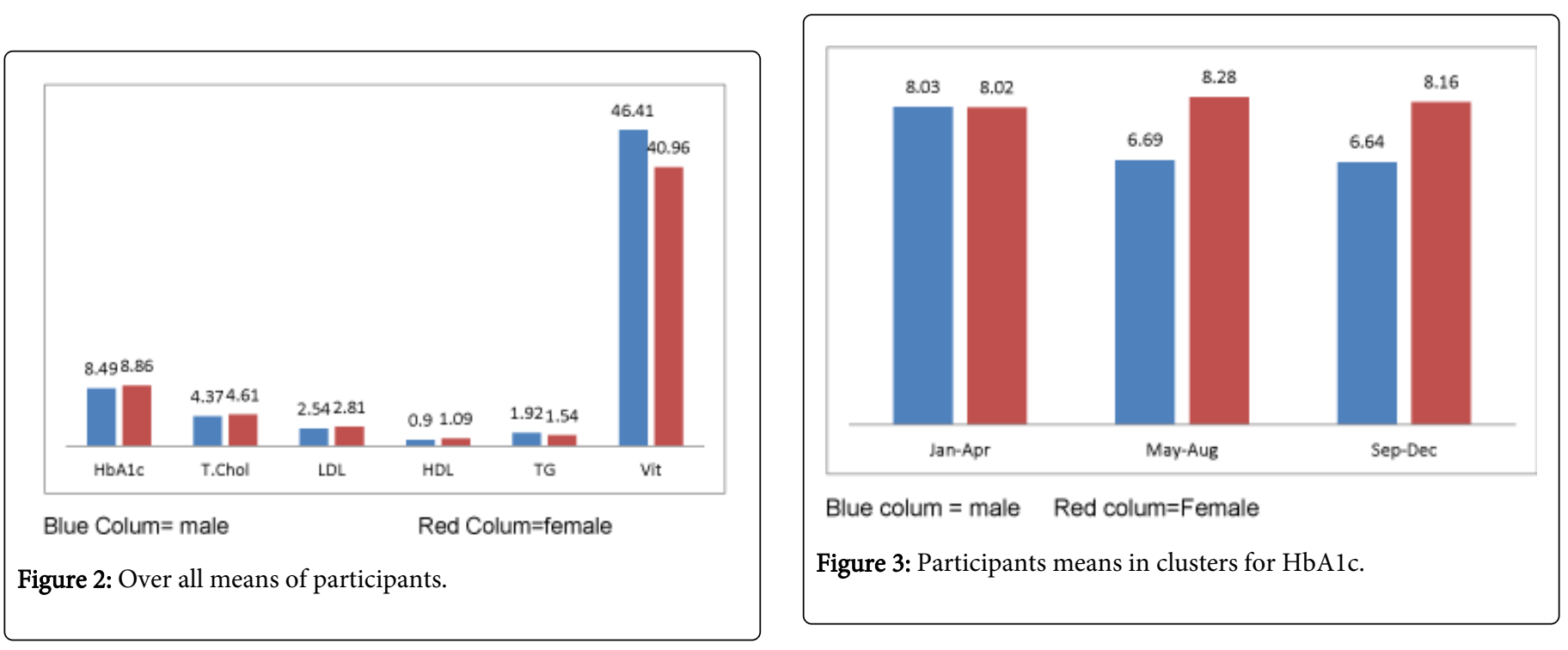


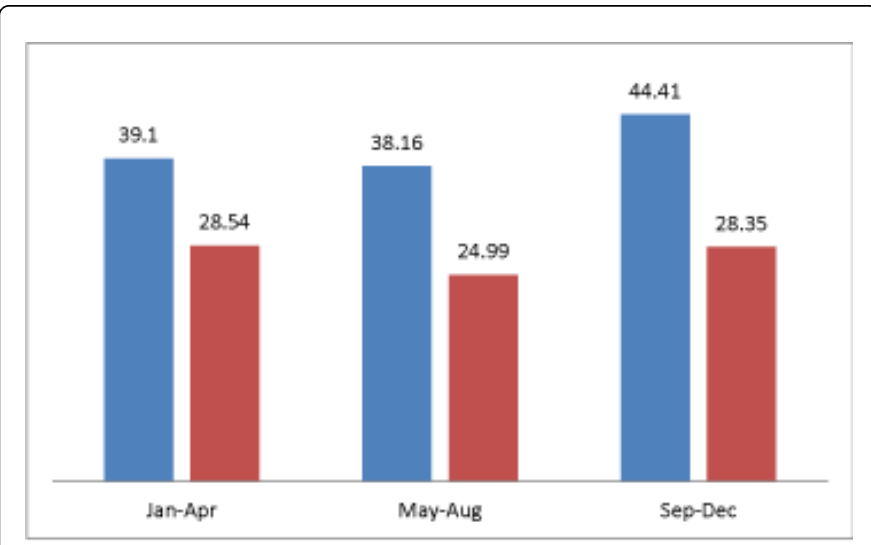

Blue colum $=$ male $\quad$ Red colum $=$ Female

Figure 4: Participants means in cluster for Vit D.

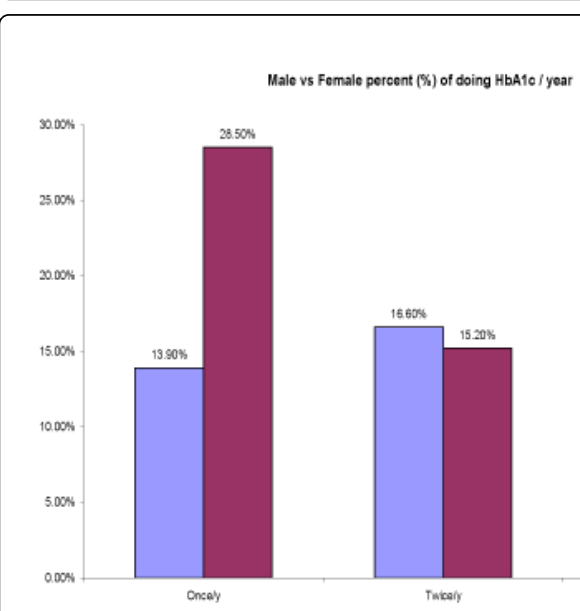

Red Colum $=$ Female

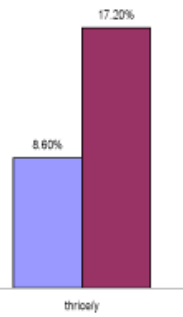

Blue Colum = Male

Figure 5: Male vs. Female percent of doing $\mathrm{HbAlc} /$ year.

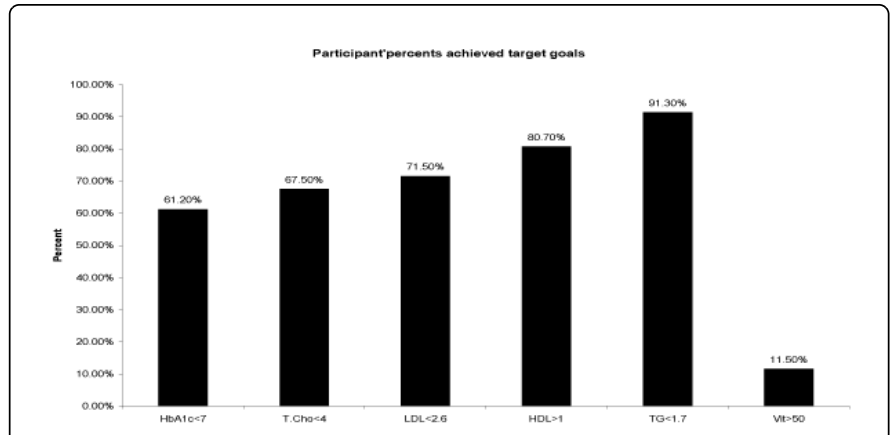

Figure 6: Participants percents achieved ADA target goals.

It was interestedly to know that $42.4 \%$ (128 subjects) did HbAlc once per year, $31.8 \%$ (96 subjects) did HbAlc twice per year and $25.8 \%$ (78 subjects) did HbAlc did HbAlc thrice per year. Majority of subjects did HbAlc thrice per year were male subjects (52 male subjects' vs 26 female subjects) (Table 7) (Figure 5).

\begin{tabular}{|l|l|l|l|}
\hline & Once/year & Twice/year & Thrice/year \\
\hline Over all & $128(42.4 \%)$ & $96(31.8 \%)$ & $78(25.8 \%)$ \\
\hline Male & $42(13.9 \%)$ & $50(16.6 \%)$ & $26(8.6 \%)$ \\
\hline Female & $86(28.5 \%)$ & $46(15.2 \%)$ & $52(17.2)$ \\
\hline
\end{tabular}

Table 7: Number of participants did HbAlc per year.

Interestedly, $61.2 \%$ of participants achieve $\mathrm{HbA1c} \mathrm{ADA}$ target goal. Male participants achieve better than female participants $(63.6 \%$ vs $59.9 \%)$ as well as in LDL ADA target goal (74.5\% vs $69.8 \%$ ) (Table 8 ) (Figure 6).

\begin{tabular}{|c|c|c|c|c|c|c|}
\hline & HbA1c $<7 \%$ & T.Chol $<4 \mathrm{mmol} / \mathrm{L}$ & $\mathrm{LDL}<2.6 \mathrm{mmol} / \mathrm{L}$ & $\begin{array}{l}\text { HDL } \\
<1 \mathrm{mmol} . \mathrm{L} \text { (male) } \\
<1.3 \mathrm{mmol} / \mathrm{L} \text { (female) }\end{array}$ & $\mathrm{TG}<1.7 \mathrm{mmol} / \mathrm{L}$ & Vit D nmol/L \\
\hline $\begin{array}{ll}\text { Total } & (302 \\
\text { subjects }) & \end{array}$ & $185(61.2 \%)$ & $204(67.5 \%)$ & 216 (71.5\%) & 244 (80.7\%) & 276 (91.3\%) & $\begin{array}{l}<2521(6.9 \%) \text { subjects } \\
>5035(11.5 \%) \text { subjects }\end{array}$ \\
\hline $\begin{array}{l}\text { Male } \\
\text { subjects })\end{array}$ & 70 (63.6\%) & 75 (68.5\%) & 82 (74.5\%) & $\begin{array}{l}88 \\
(80 \%)\end{array}$ & $100(90.1 \%)$ & $\begin{array}{l}<255(4.5 \%) \text { subjects } \\
>5010(9.1 \%) \text { subjects }\end{array}$ \\
\hline $\begin{array}{l}\begin{array}{l}\text { Female } \\
\text { subjects })\end{array} \quad(192 \\
\end{array}$ & 115 (59.9\%) & $129(67.2 \%)$ & 134 (69.8\%) & $156(81.3 \%)$ & $176(91.7 \%)$ & $\begin{array}{l}<2516(8.3 \%) \text { subjects } \\
>5010(5.2 \%) \text { subjects }\end{array}$ \\
\hline
\end{tabular}

Table 8: Percents of participants meet ADA target goals.

\section{Discussion}

Many factors affected diabetes control in primary health care. Glycemic and metabolic control is a real challenge in primary health care settings.
An interested cross sectional study [6] done in Canada to provide insight into the care and treatment of type 2 diabetes in Canadian primary care settings found the mean of HbAlc was about $7.3 \%$ with $49 \%$ of patients not at target (HbAlc $\geq 7 \%$ ). In our study the mean $\mathrm{HbAlc}$ was $8.73 \pm 2.04 \%$ and $38.8 \%$ of patients not at target (HbAlc $\geq$ 
7). This variation can be explained by the quality of standards applied at Canadian primary care settings and our. It was interested to found that we have less percent of participants not meet the target. This could be explained but our small sample size.

In comparison with a multicenter cross sectional epidemiological survey [7] conducted in nine countries in Latin America, 43.2\% achieved $\mathrm{HbA} 1 \mathrm{c}<7 \%$. Interestedly to notice that the researchers in this study pointed to non compliance to recommended diet and exercise as a reason for their result. Situation was differed in our study as non compliance to recommended diet and exercise was a real challenge for us but the frequent follow up may overcome this and improve our HbAlc means. From Hungary, came another interested paper [8] recruited 679 patients under continues care where the researchers found that $42.5 \%$ of diabetic patients achieved the target of $\mathrm{HbA1c}<7 \%$ vs $61.2 \%$ in our study which is better than the study finding and in patients with dyslipidaemia, the target level of triglyceride was reached by $40.6 \%$ vs $91.3 \%$ in our study, recommended total cholesterol by $14.2 \%$ vs $67.7 \%$ in our study and the HDL cholesterol by $71.8 \%$ vs $80.7 \%$ in our study this could be explained by the different nature of food intake and social habits such as alcohol intake in Hungary people. Another study done in Korea [9] to evaluate LDL-cholesterol after medication. Researchers found that $87.6 \%$ of participants attained their LDL-cholesterol goal vs $71.5 \%$ in our study. Interestedly, adherence to medication was strongly associated with the achievement of target LDL cholesterol in Korean study as well as our study.

Another interested small sized retrospective study [10] recruited 177 subjects from Oman, most of subjects were female (60\%). This study found that only $35 \%$ of participants attained $\mathrm{HbAlc}$ target goal $(\mathrm{HbA} 1 \mathrm{c}<7 \%)$ vs $61.2 \%$ in our study.

Another cross sectional study was done in King Khalid University Hospital [11]. In these study 1520 subjects was selected randomly. Medical charts were reviewed and data collected and analyzed. The overall glycemic control as evaluated by $\mathrm{HbAlc}<7 \%$ was found to be $39.7 \%$ which was far to our result (61.2\%). The small sample size and frequent follow up with the participants may explain this. For lipid targets there were significant differences. In this study and our study, for TG<1.7 $\mathrm{mmol} / \mathrm{l}$, LDL $2.6 \mathrm{mmol} / \mathrm{l}$ and $\mathrm{HDL}>1 \mathrm{mmol} / \mathrm{l}$, they are $56.6 \%$ vs $91.3 \%, 24.6 \%$ vs $71.5 \%$ and $54.2 \%$ vs $80.7 \%$ (P value $<0.0001)$.

Another study [12] done in Saudi Arabia enquiry about meeting the American diabetic association standards of diabetic care found that in 1180 diabetic patients, only $21.8 \%$ achieved $\mathrm{HbAlc}$ goal target of $<7 \%$ and $55.5 \%$ achieved LDL target goal $<2.6 \mathrm{mmol} / \mathrm{l}$ which are lower than our results. This can be explained by good adherence to treatment and frequent follow up with our participants.

Interested study done at military primary care setting in Saudi Arabia [13] looked for the quality of care for type 2 diabetes mellitus in military primary care setting. This study recruited 543 subjects and found that only $10.4 \%$ achieved $\mathrm{HbA} 1 \mathrm{c}$ target goal $<7 \%$. This was very low than our study level $38.8 \%$, although there was reported less level of goal target achievement in a primary care practice in Riyadh, Saudi Arabia, which ranged between $7.65 \%$ and $7.84 \%$ [14]. In the previous study [13], the researchers reported that $95.6 \%$ did HbAlc twice annually while it was $31.8 \%$ in our study. In our study $42.4 \%$ did HbAlc once annually and $25.8 \%$ did it thrice annually. This may explain partially poor glycemic control among our subjects.

A cross-sectional study [15] was carried out on a total of 465 young adult Saudi females aged 19 to 40 years old who were selected from primary health care centers of King Abdulaziz medical city, Riyadh, KSA , 25-hydroxy vitamin D [25(OH)D], Parathyroid hormone (PTH) and bone biochemical parameter were measured. Vit $\mathrm{D}$ mean level was found to be $18.34 \pm 8.2 \mathrm{nmol} / \mathrm{L}$ while it was $42.32 \pm 22.56 \mathrm{nmol} / \mathrm{l}$ in our study. This could be explained that our participants were both male and female while this study only recruited female. Female participants in our study had mean of $40.96 \pm 18.98 \mathrm{nmol} / \mathrm{l}$. Again this is higher than the mean found in the previous study, but factors affected Vit D could have a role on this.

There were some limitations in our study; the sample size was small (302 subjects), large community base study recommended. Most of our participants were female (63.5\%).

\section{Conclusion}

In conclusion, the results of this study indicate poor glycemic control and relatively accepted lipid control in primary care setting. Adoption of more intensive, early and comprehensive management is highly recommended in primary care.

\section{Conflict of Interest}

I had declared that I have no any conflict of interest. Also I had no support from any organization for the submitted work; no financial relationships with any organizations that might have an interest in the submitted work in the previous three years and any other relationships or activities that could appear to have influenced the submitted work.

\section{Acknowledgement}

The author would like to thank Mrs Mayada Abubakr Alsaeed for her valuable help in editing and organizing this paper.

\section{References}

1. Groop L (2002) Epidemiology and Clinical Heterogeneity of Adult-Onset diabetes. In: Wass, $\mathrm{J} \mathrm{A} \mathrm{H}$ and Shalet (Eds) Oxford Textbook of Endocrinology and Diabetes. Oxford University Press. pp 1688-1695.

2. http://www.publications.doh.gov.uk/nsf/diabetes

3. Krentz AJ, Bailey C J (2001) Type 2 diabetes in practice. RSM Press, London.

4. Williams G, Pickup JC (2004) Handbook of diabetes, 3rd edition. Oxford: Blackwell Publishing Ltd.American Diabetes Association.

5. Harris SB, Ekoé JM, Zdanowicz Y, Webster-Bogaert S (2005) Glycemic control and morbidity in the Canadian primary care setting (results of the diabetes in Canada evaluation study). Diabetes Res Clin Pract 70: 90-97.

6. Lopez Stewart G, Tambascia M, Rosas Guzmán J, Etchegoyen F, Ortega Carrión J, et al. (2007) Control of type 2 diabetes mellitus among general practitioners in private practice in nine countries of Latin America. Rev Panam Salud Publica 22: 12-20.

7. Szigethy E, Jancsó Z, Móczár C, Ilyés I, Kovács E, et al. (2013) Primary care of patients with high cardiovascular risk : Blood pressure, lipid and diabetic target levels and their achievement in Hungary. Wien Klin Wochenschr 125: 371-380.

8. Lee JA, Sunwoo S, Kim YS, Oh HJ, Kang HC, et al. (2013) Achieving recommended low density lipoprotein cholesterol goals and the factors associated with target achievement of hypercholesterolemia patients with rosuvastatin in primary care. Curr Med Res Opin 29: 751-760.

9. Al Balushi KA, Al-Haddabi M, Al-Zakwani I, Al Za'abi M (2014) Glycemic control among patients with type 2 diabetes at a primary health care center in Oman. Prim Care Diabetes . 
Citation: Ahmed AA, Qurashi A (2014) Do we Achieve the Targets for Diabetic Patients; Deep Looks to Primary Care Practice. J Gen Pract 2: 152. doi:10.4172/2329-9126.1000152

Page 7 of 7

10. Al-Rowais NA (2013) Glycemic control in diabetic patients in King Khalid University Hospital (KKUH) - Riyadh - Saudi Arabia. Saud Pharm J.

11. Kharal M, Al-Hajjaj A, Al-Ammri M, Al-Mardawi G, Tamim HM, et al (2010) Meeting the American Diabetic Association standards of diabetic care. Saudi J Kidney Dis Transpl 21: 678-685.

12. Ali H Guzu , Abdullah Al Shehri , Hesham I Al Khashan, Adel M Mishriky (2012) Quality of care for type 2 diabetes mellitus in a military primary care setting. J Clin Outcomes Manager 19:551-556.
13. Alfadda AA, Bin-Abdulrahman KA, Saad HA, Mendoza CD, AngkayaBagayawa FF, et al. (2011) Effect of an intervention to improve the management of patients with diabetes in primary care practice. Saudi Med J 32: 36-40.

14. Al-Mogbel ES (2012) Vitamin D status among Adult Saudi Females visiting Primary Health Care Clinics. Int J Health Sci (Qassim) 6: 116-126. 